\title{
Visual Aids as Response Facilitators in Dialogue Journals
}

\author{
M. GREGORY TWEEDIE \\ University of Calgary \\ ROSWITA DRESSLER \\ University of Calgary
}

\begin{abstract}
Dialogue journals are useful pedagogical tools for developing communicative written fluency. While instructors often respond to student writing by modeling, questioning and providing feedback, visual aids are also sometimes used to enhance communication. In this study, findings from an examination of 12 adult English Language Learners' dialogue journals reveal that the instructor demonstrated an understanding of visual aids, which included instructor-drawn pictures and textual enhancements. Some students responded with hand-drawn pictures of their own and noted that visuals increased their interest in writing and helped them to understand unfamiliar topics. The use of instructor-drawn pictures and textual enhancements as a part of dialogue journals facilitates communication and strengthens the rapport-building for which dialogue journals are well-known.
\end{abstract}

\section{Introduction}

Dialogue journals allow English Language Learners (ELLs) to focus on communication in second language writing without a preoccupation with accuracy. These journals involve the back and forth exchange of instructor writing and student writing without explicit correction. In a previous study with adult Japanese students, dialogue journals allowed for the instructor-student rapport-building necessary for students to feel comfortable learning and taking risks in their second language writing (Dressler \& Tweedie, 2016). Dialogue journals serve as a pedagogical strategy for increasing writing fluency, once students and instructors have established this written rapport.

Surprisingly, little research has been done on ways to facilitate the dialogue in dialogue journals beyond a focus on the textual. The communicative nature of these second language writing tools would allow for the use of visual aids: defined as teacher-drawn and student-drawn pictures, or textual enhancements. Textual enhancements include arrows, underlining, different fonts/colours, or formatting specific to a particular genre (e.g., letters, tests, schedules). Certainly, teachers have long provided feedback to student writers through the use of textual markups like underlining, circling, using a different colouredpen (usually red!), writing marginal comments and the like (Ferris, 2014), but such enhancements are typically utilized for corrective feedback; here we differentiate between this traditional function and the role of textual enhancements in facilitating student-teacher dialogue. Such visual aids may make a difference in the understanding and rapport building that takes place in dialogue journal writing.

This study examines the use of visual aids in the dialogue journals of 12 adults ELLs on a short-term study abroad sojourn. The results shed light on how teacher-drawn pictures and textual enhancements (as defined above) can be used as response facilitators 
that enhance the modeling, questioning/requesting, and provision of feedback that takes place in these writing exchanges. The results expand our understanding of how ELL instructors use dialogue journals and the role of pictures and textual enhancement within this practice.

\section{Literature Review}

Dialogue journals have likely been in use by instructors for a long time, but the early works of Kreeft (1984); Staton, Shuy, Peyton and Reed (1988); Peyton and Reed (1990); Peyton and Staton (1993); and Peyton (1997) are often credited with bringing this form of journal writing to the mainstream of educational practice, providing both working definitions and concrete steps for effective practice. These researchers describe dialogue journals as written conversations involving regular communication between instructor and student over the duration of a course of study. Unlike traditional classroom writing assignments, participants make choices on matters like genre, style, length of response, and topic. The overriding goal is to foster authentic communication; at times journal topics may link directly to the curriculum of study, and some corrective feedback may be provided by the instructor, but these are not to be subsumed by the overarching communicative aim. The type of interactive communication utilized by dialogue journals, where students and teachers initiate topics of interest through written dialogic conversation in a promptresponse cycle, contrasts with much of what has traditionally constituted teacher-student written interaction, whether assignments penned for an "imagined audience" (Mansor, Shafie, Maesin, Nayan, \& Osman, 2011), or a focus on error correction. As a result, these journals have emerged as popular tools for promoting writing for communication.

Research concerning dialogue journals has demonstrated a number of benefits as diverse as: fostering instructor-student rapport (Burton \& Carroll, 2001; Lucas, 1990); enhancing various aspects of language acquisition (Holmes \& Moulton, 1995); and developing critical literacy practices (Ghahremani-Ghajara \& Mirhosseini, 2005). From their first documented use in the 1980s with sixth grade students in California (Peyton \& Reed, 1990; Peyton \& Staton, 1993), dialogue journals are now employed as a pedagogical tool across a wide range of learner ages, literacy levels and areas of study. Consider, for example, the application of dialogue journals in undergraduate chemical engineering education (Korgel, 2002) or the teaching of disenfranchised middle school science students (Hanrahan, 1999). Dialogue journals can be effective rapport builders in the compressed time frame of a short-term sojourn (Dressler \& Tweedie, 2016). These diverse benefits speak to the utility of dialogue journals in the classroom.

Typically, since dialogue journals feature a written conversation between instructor and student, they are not assessed - unlike many writing assignments in educational settings. The lack of assessment changes the role of the instructor from judge to facilitator. Understanding, whether of self or the other party in the exchange, is often gained in a way that is atypical of classroom interactions (Casanave, 2011). The absence of grading in the writing reduces the students' feelings of evaluation and paves the way for authentic instructor-student interaction to take place.

The critical role of the instructor in facilitating effective interaction in dialogue journals was recognized early on in the literature. Staton (1987) insists that "the access to the instructor's mind, and to an interactive, personalized response makes the dialogue journals work" (p. 47; emphasis in original). Part of personalizing the response may be in 
the use of pictures, arrows or other graphics to enhance the communication between instructor and student. In light of the instructor's role in promoting dialogue, the use of such visual aids may need to begin with the instructor.

\section{Visual Aids}

Visual aids within dialogue journals have been considered in other literature as part of the student's visual contributions to self-expression in dialogue journals (e.g., Daniels \& Daniels, 2013; Stillman, Anderson, \& Struthers, 2014). Stillman, Anderson and Struthers (2014), for instance, present dialogue journals as a means of "returning to reciprocity" by providing examples of student-drawn illustrations to which the teacher responds with written comments or questions. The aforementioned authors recount a journal discussion where a teacher encountered "a reluctant writer who loved art". The teacher encouraged the use of the student's artistic talents by indicating - in written text: "I can just imagine the drawings you would create to accompany this story" (p. 152). Similarly, Daniels and Daniels (2013) "encourage drawing as a way to participate in a written conversation" (p. 151; emphasis in original) in reference to students. The literature clearly recognizes the role of student drawing as part of self-expression in dialogue journals.

Encouragement for teachers to contribute visually to the written conversation is noticeably absent in the literature, even in literature that encourages student drawing. An exception to this absence is Peyton's (1993) prescription of instructor drawings as a response to pictures from students with lower levels of literacy, but only as a precursor for a "move to letters, words, and longer texts ... when students feel ready" (p. 4). In other words, drawing is encouraged, but only as a transition to increased writing. Beyond Peyton (1993), the literature appears to overlook the potential contributions of teachers who might employ their own artistic self-expression.

In Werderich's (2006) study of middle school English Language Arts teachers, visual aids was the term for one of four response facilitators teachers used to respond to students. She defined these visual aids as "procedural reinforcements" (cf. Jewell \& Pratt, 1999) which exhort students to pay attention to a previously provided writing template, provide correction in spelling or grammar, or model appropriate paragraphing. While likely appropriate and necessary in many circumstances, the definition of visual aids as procedural reinforcements is problematic because it ignores the possibility of teacher or student-drawn pictures. Defined in this way, these visual aids draw the student's attention outside of the dialogue journal to authoritative sources such as handouts, classroom posters and dictionaries. This outside focus has the potential to disrupt the teacher-student conversation, which is widely seen as a core element of dialogue journals (Peyton, 1997; Peyton \& Staton, 1993).

As shown, little research on dialogue journals includes an examination of drawings of pictures or use of textual enhancements. Consider the many possibilities for such visual aids. Drawings can range from stick figures to elaborate illustrations. Textual enhancements can include simple hand-drawn pictures, emoji, speech bubbles, arrows, underlining, contrasting text colors, non-standard layout and the like. Anecdotal observations and reflective teaching practices over the years have indicated that the inclusion of visual aids of this type enhance the rapport-building function of dialogue journals. This formal study of the use of visual aids, defined as drawing and textual 
enhancements, sheds light on their role in the facilitation of the dialogue journal conversation.

\section{Theoretical Framework}

Werderich's (2006) response facilitator framework holds promise for this study as it draws from the work of teachers experienced in working with dialogue journals. In her research on teachers' use of dialogue journals, she proposed a model of teacher's response processes (p. 54). Within this larger model, she proposed a four-quadrant circle of response facilitators (see Figure 1). This model presents the response facilitators as four distinct categories: modeling, questioning/requesting, providing feedback, and using visual aids (procedural reinforcements). Modeling involves scaffolding the learning by using the same formats and structures one encourages the students to employ. Questioning/requesting was used to redirect student thinking or solicit clarification. Feedback took the form of encouragement, compliments, recommendations and answers to student questions. Visual aids, as mentioned earlier, was the response facilitator category Werderich coined for references teachers made to posters and handouts.

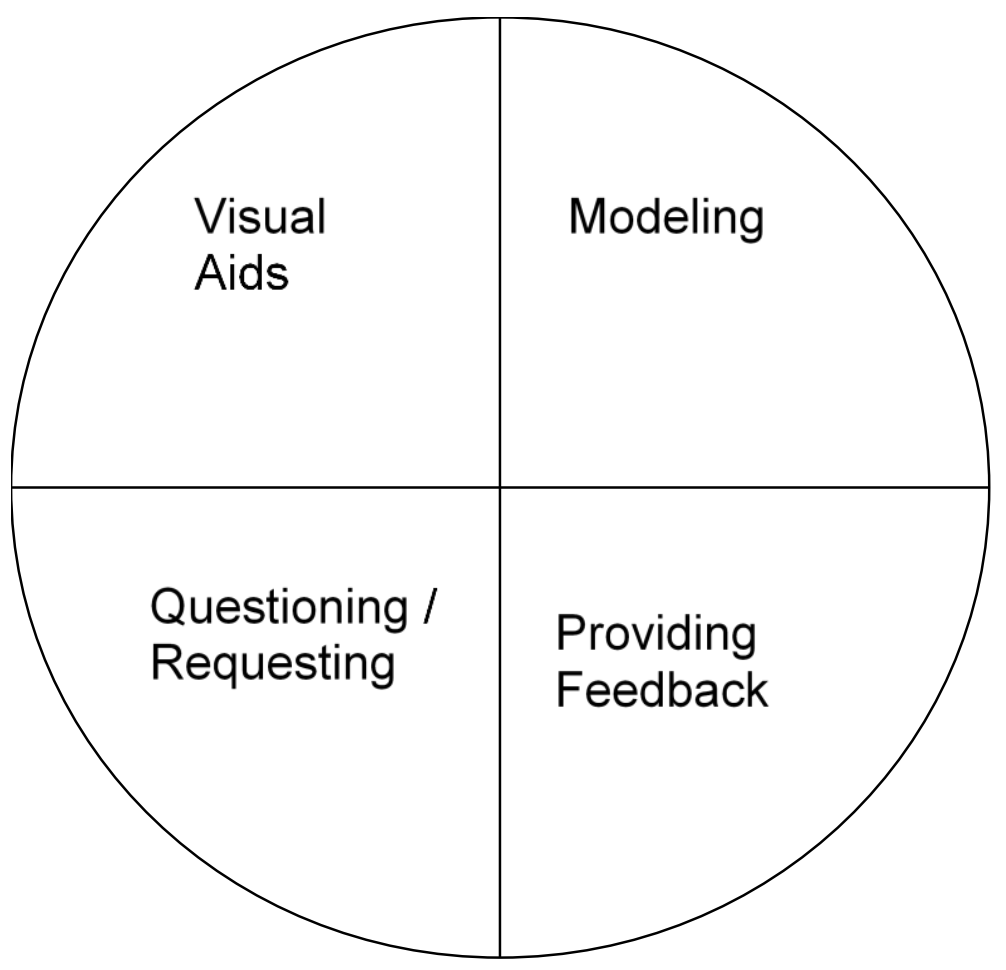

Figure 1. Werderich's Response Facilitators Model (adapted)

Since Werderich's (2006) definition for visual aids is limited to procedural reinforcements, we propose a modification to the definition of visual aids in the above model to include drawing and textual enhancements. To investigate how visual aids are used in dialogue journals, when defined in this manner, we looked at visual aids on their own (stand-alone visual aids) and in conjunction with the remaining three response facilitators (modeling, questioning/requesting, providing feedback). Since we concur with 
Werderich (2006) that these response facilitators occur through the textual responses of ELL instructors, we did not focus on textual responses; rather, we are interested in investigating the following:

1. How do visual aids, when defined drawings and textual enhancements, act as standalone response facilitators in dialogue journals?

2. How do visual aids act as response facilitators when used in conjunction with modeling; questioning/requesting; providing feedback?

\section{Methodology}

\section{Participants}

This study was conducted in a short-term study abroad program that brings 10 students a year from Japan to a Canadian university campus for a four-week stay. For the students in this program, this is usually their first trip abroad. All are students in an education university; they range in age from 18-24 years. Often coming from rural areas, these students are beginning to intermediate ELLs.

In their dialogue journals the students reveal that in their previous experience learning English "it is rare to be taught English by native speaker in Japan" (Akari ${ }^{1}$ ). Mei commented that "actually Japanese are too much afraid of making mistakes" which concurs with Yuna's personal observation that "writing English was only exam when I was a high school students. So I was skeary [scared] that I made mistake". These comments were made in comparing their feelings about writing in previous teaching contexts to their reaction to the dialogue journals, which Mei summed up as "this is a very good method of teaching for students in Japan”.

\section{Research Context}

Author 1 is the ELL Instructor and Author 2 is the faculty member tasked with organizing the cultural component of the visit. Author 1 decided to use dialogue journals as one element of the regular ELL classes for these students. He began each journal with a prompt and allowed the written conversation to go in the direction that the students took it. He used hand-drawn pictures and textual enhancements that we define as visual aids for this study. The pictures are drawn from Wright's (1984) 1000 Pictures for teachers to copy, a resource which he had made use of for many years.

Dialogue journals were introduced at the beginning of the four-week sojourn. Each student was given a notebook in which the instructor had already written a personalized opening prompt reminding the student that dialogue journals are a conversation that stresses writing fluency over accuracy and that he would not be correcting their spelling or grammar. Each opening entry started with a question such as "would you mind sharing a surprising fact (or two) about you?" Students wrote their responses in class for a period of approximately 30 minutes. The instructor wrote his replies outside of class and returned the notebooks once a week. Each opening question was unique and topics within each journal diverged as the students or the instructor moved the conversation forward. Writing sessions took place 4 times in each of the short-term sojourns. In this data for this study, the instructor wrote 62 different journal entries, and included visual aids in 59 of them.

\footnotetext{
${ }^{1}$ All names are pseudonyms.
} 


\section{Data Collection}

For this study, we received institutional ethics approval to request consent from the students in two separate years of the program to analyze their dialogue journals. At the beginning of the sojourn, the study was explained to them by one of our Japanese-speaking colleagues. At the end of the sojourn, scans were made of all journals and the originals sent home with the students. Upon their return to Japan, they received an email from that same colleague requesting permission to use the scans as data. The dialogue journals of those who responded were used in the study. Permission was granted by 12 students $(8 / 10$ from the first group we studied, and 4/10 from the second).

\section{Data Analysis}

In all, 12 student dialogue journals were analyzed. First, the chronology of teacherstudent dialogue was recorded on a spreadsheet, organized by conversational turns. Next, all visual aids were identified and classified as instructor-drawn pictures, instructor-drawn textual enhancements, student-drawn pictures or student-drawn textual enhancements. These visual aids were then colour-coded to differentiate visually between teacher and student moves. Interactions were further coded as either a prompt $(\mathrm{P})$ or a response to a prompt (R) to document whether students responded to the use of visual aids. The data were analyzed to determine if they facilitated a response on their own or in interaction between the response facilitator visual aids with Werderich's (2006) other response facilitators: modeling; questioning/ requesting; and providing feedback. Each researcher analyzed the data individually, before coming together to share analysis for further insights and reach interpretive consensus.

A total of 59 visual aids were drawn by the teacher, and 40 by students. 33 items were coded $(\mathrm{P})$, while 88 responses $(\mathrm{R})$ were recorded in reply to those prompts. 48 textual enhancements were used; some in connection with pictures and some in isolation. This analysis shed light on the use of visual aids as response facilitators, using an alternate definition which includes teacher- and student-drawn pictures and textual enhancements, and demonstrates how visual aids serve the functions of other response facilitators.

Here is an example of how a dialogue journal with visual aids looks. Imagine a paragraph written by an instructor, complete with a picture prompt. Add to that arrows, brackets and other textual enhancements that draw the student's attention to important aspects of the content. Then imagine a student's written response that follows, to which the instructor will add marginal comments and arrows when writing his or her subsequent response (see Figure 2). 


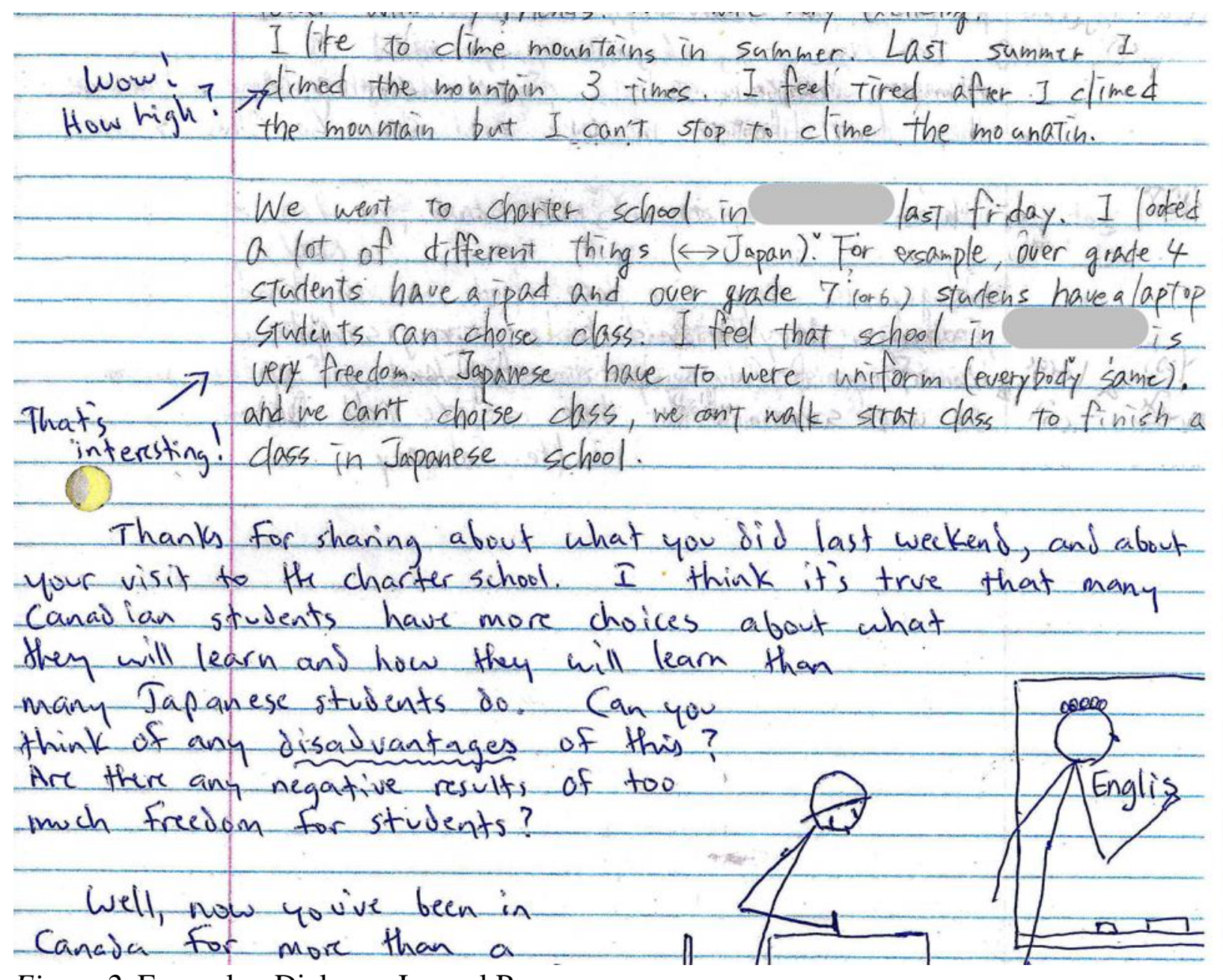

Figure 2. Example - Dialogue Journal Page

The student is writing in response to a prompt question on the previous page ${ }^{2}$. When the instructor responded to what she had written, comments were made in the margin with arrows pointing to what the student had written that had prompted this response. The teacher drawings enhance the text with underlining (in this case the wavy underlining of the word "disadvantages") which points the student to a key word in the question. A drawing of an instructor writing on a board while the seated student is working was added. This visual aid is both in response to what the student has written about and serves to

\footnotetext{
${ }^{2}$ As with any communication, even simple drawings run the risk of conveying unintended messages. A student might interpret the interaction in the classroom depicted in Figure 2 as a traditional instructor-centered classroom. The instructor writes on the board the word English, situating this classroom as one in which English has power and is the domain of the instructor. In response, the obedient student, head bent over his or her work, furiously copies what the instructor writes. Two points can be offered in response to this potential pitfall. First, the unintended message described above is one that emerged only after multiple readings of the data. A student, sitting down to respond to a prompt, might give only an initial glance to the picture and not arrive at this reaction. In fact, the simple drawing may reflect the student's reality, sitting at a desk in an EFL classroom; the non-gendered stick figures might represent a myriad of possible instructor-student dyads. Second, unclear meanings of visuals in dialogue journals can prompt further questioning and discussion from the student, effectively generating more written language for student-instructor interaction.
} 
prompt the student to write about what she sees as disadvantages to choice in a school system. In this way, visual aids as response facilitators offer both affordances and challenges.

\section{Findings}

Returning to our research questions, our findings reveal that visual aids functioned both as stand-alone facilitators and in conjunction with other response facilitators (i.e., modeling, providing feedback, questioning/requesting). Stand-alone visual aids were either prompts to elicit responses or responses to previous prompts. Visual aids in conjunction with another response facilitator were primarily used by the instructor. While students did not prompt the instructor with visual aids used in conjunction with other response facilitators, they usually responded to his efforts to engage them.

\section{Visual aids as stand-alone response facilitators}

The data revealed that visual aids served as response facilitators within the dialogue journals of the 12 students. These simple pictures and textual enhancements acted as prompts or responses to the written text. For example, the three stick figures in Figure 3 work with the text "I look forward to getting to know you through these dialogue journals" to underscore the dialogic aspect of the written conversation in the journals. Figure 4 illustrates how the instructor's comments in the margins are linked to the text through the use of arrows, which indicate exactly which portions of the student's writing he is responding to. Both types of visual aids enhance the clarity of the instructor's written prompts or responses.

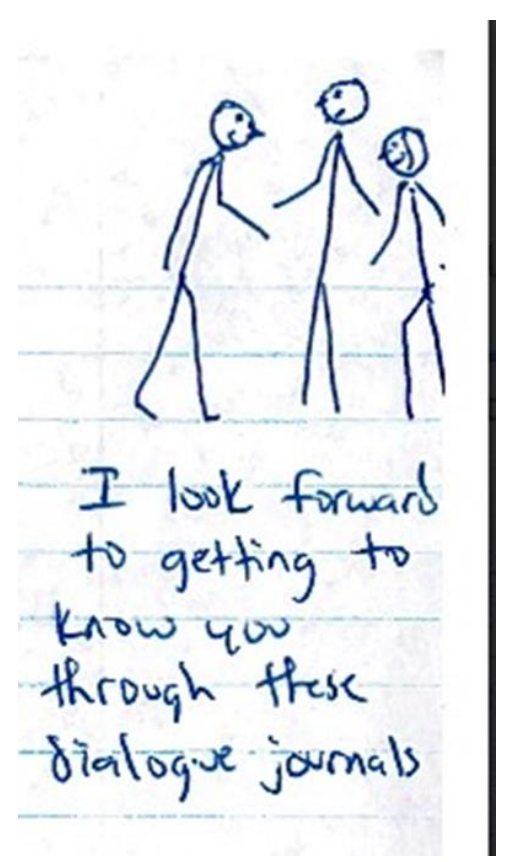

Figure 3. Stick Figures - Visual Aids Working with Texts 


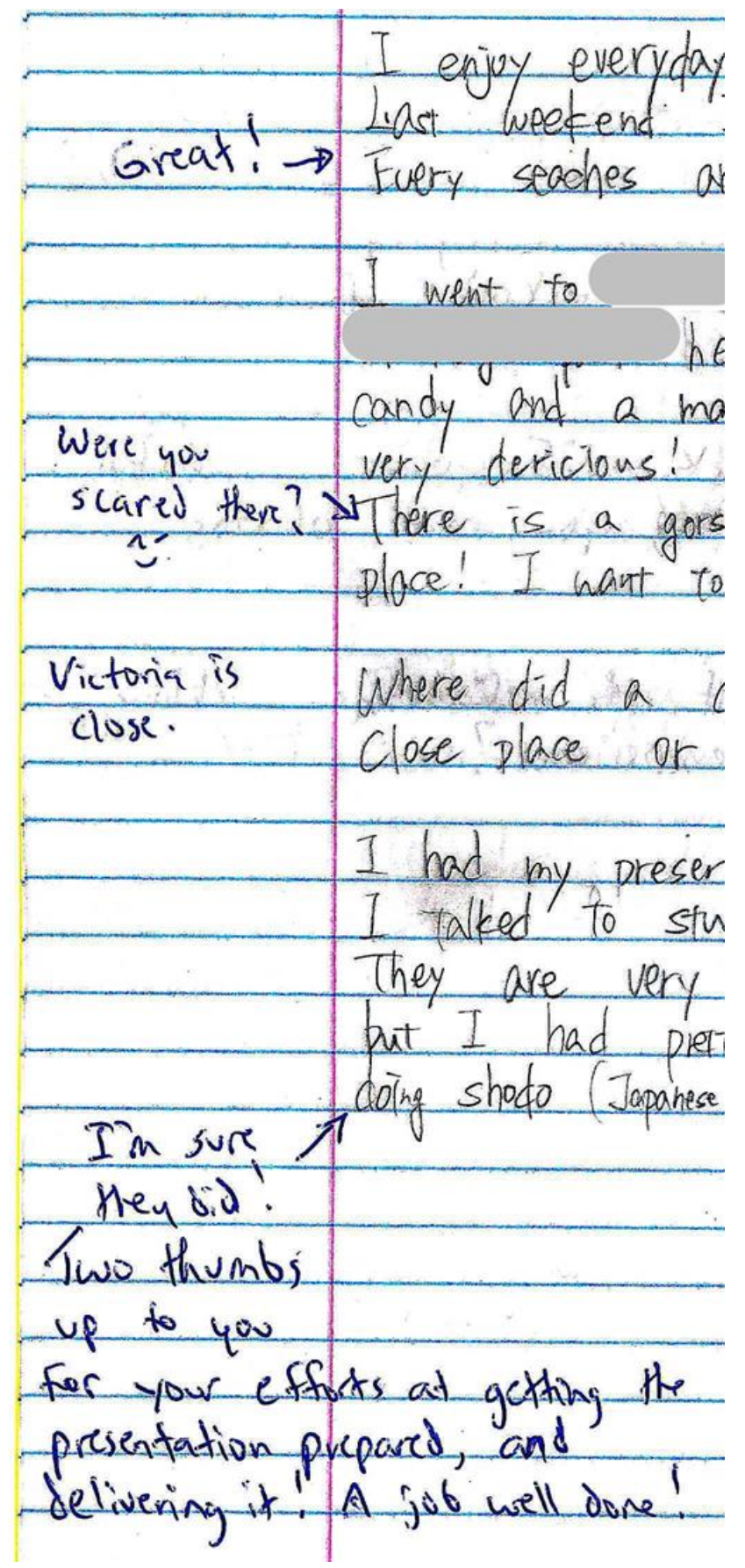

Figure 4. Examples of Textual Enhancements

Some students initiated their own use of visual aids to enhance their dialogue journal entries. Mei drew pictures and captioned them "what I love is". These drawings, in addition to her label below each picture, served to communicate an unsolicited expression of her personality (see Figure 5). 


\section{Good bye is"}

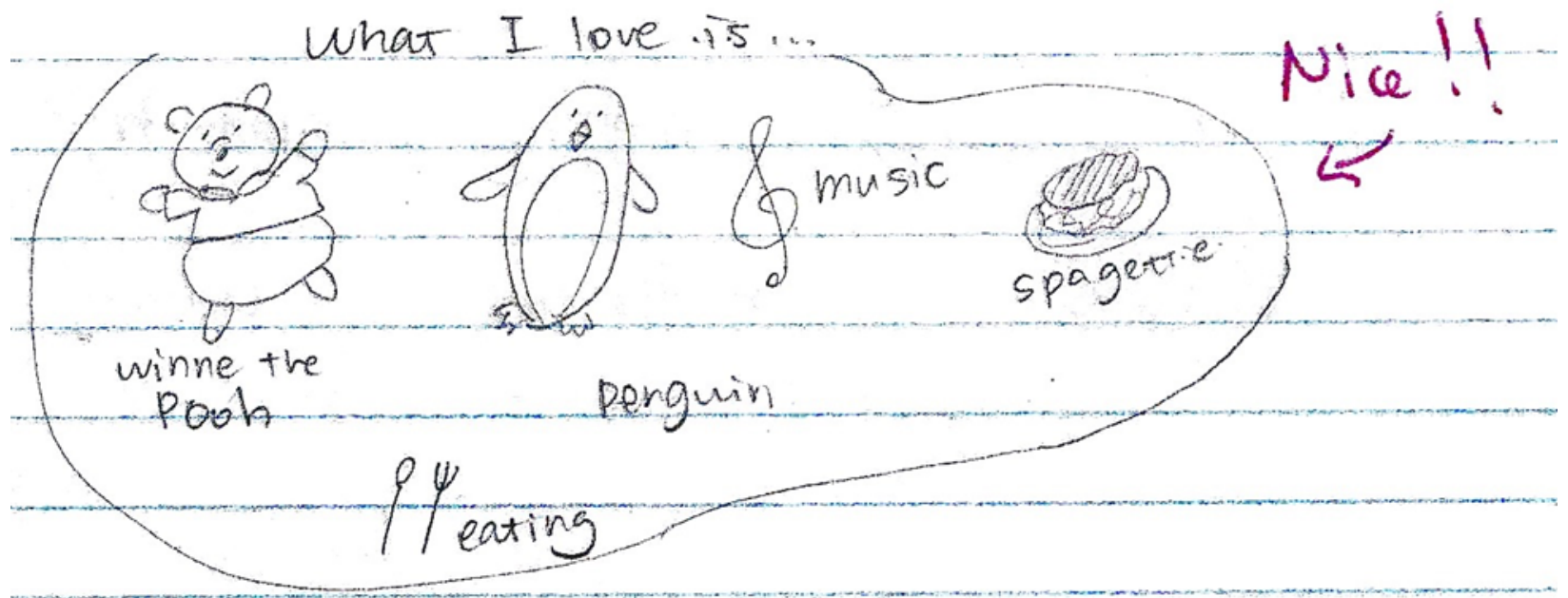

Figure 5. Mei's Use of Pictures - Student Use of Visual Aids in Dialogue Journals (1)

Another example of student-initiated visual aids is found in one of Yuna's entries, where she augmented her contribution on how she had once climbed a mountain, by illustrating it with a mountain climber and the word "hard" (see Figure 6). Neither of these visual aids were necessary for the instructor to understand her writing, but they demonstrate that Yuna comprehended the role that pictures can have in facilitating the reader's understanding.

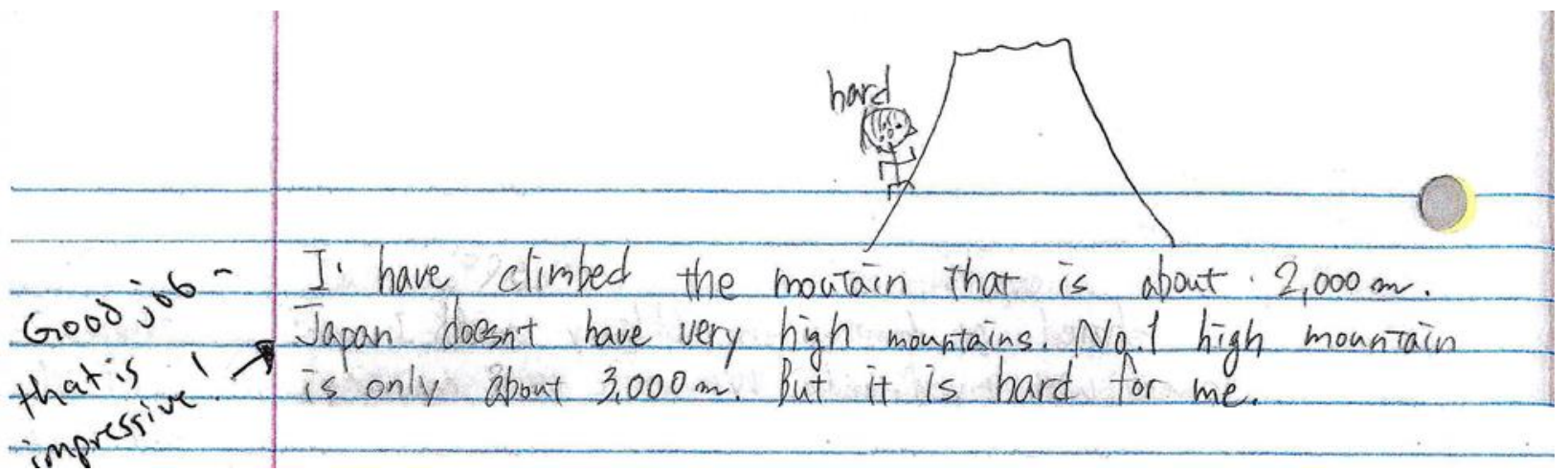

Figure 6. Yuna's Mountain Climber - Student Use of Visual Aids in Dialogue Journals (2)

In a similar way, Kota embedded a visual aid in a description of his hockey team as a means of explaining what position he played (see Figure 7). His diagram is more integral to the understanding of his writing because he lacked the domain-specific vocabulary in English around the game of ice hockey. 


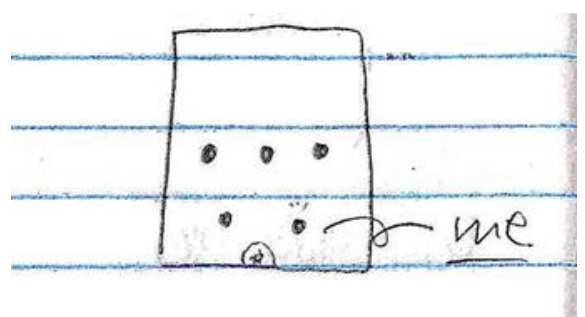

Figure 7. Kota's Hockey Team - Student Use of Visual Aids in Dialogue Journals (3)

The instructor's use of visual aids opened up the students to use drawings and textual enhancements to strengthen the communication of their dialogue journals. In the last dialogue journal entry, he asked the students to comment on the use of pictures. As expected, some students highlighted the rapport-building role of visual aids. Mei said, "I was looking forward to your pictures" and Kota noted "A picture effect [sic] on student's feeling". This rapport-building function was one of the strengths noted by the students.

The students also commented on how instructor-drawn visual aids created interest in reading and writing. One student wrote, "Sometimes, students are not interested in reading and writing, but some pictures atract [sic] students" (Kota). Yuna expressed a similar sentiment: "pictures made me funny! I think that all sentences is boring." Mei highlighted: "If there are no pictures in journal maybe I feel serious". These comments highlight the motivational aspect of visual aids.

Finally, students affirmed the role of instructor-drawn pictures in constructing meaning. Mei felt that "the picture makes [it] easier to understand the journal even though there are some words that I don't know". Similarly, Akari wrote that "pictures helped me to understand" and Yuna commented that "pictures helped me to understand sentences". These students indicated that the pictures scaffolded their understanding of the written text.

This explanatory function of instructor-produced visual aids came as a surprise. Instructors sometimes make the mistake of assuming students understand unless they receive direct feedback that demonstrates otherwise. Textual comments may not have been comprehensible on their own, but were being comprehended, because students were utilizing the pictures to aid in meaning-making. This explanatory function further strengthens the case for including instructor-created pictures in dialogue journals.

\section{Visual aids in conjunction with other response facilitators}

The results also shed light on how visual aids can be used in combination with other response facilitators: modeling, questioning and requesting, and providing feedback (Werderich, 2006).

Modeling. In Werderich's (2006) framework, modeling is seen as the instructor referencing actions or textual forms to encourage students to express or use the same. In the dialogue journals, this can take place entirely in text form, but these examples illustrate how modeling can be supported by drawings and textual enhancements.

One example of modeling occurred when the instructor wrote of a set of multiple choice questions in his prompt. The student, Taro, received five multiple choice questions for him to guess the instructor's sporting interests. He responded with his own multiple choice "test", creating his own five questions (e.g., My position in baseball: a) pitcher b) third base c) right field). The instructor used a drawing of himself as a weightlifter and a 
picture of an American football to illustrate his questions to Taro. After Taro provided his answers to the questions, by circling A, B, C or D, the instructor provided further conversational input with red pen by circling his correct answer in red and adding commentary such as "I do love hockey, though". This playful interaction modeled a different mode of communicating getting-to-know-you questions.

Another way to encourage writing without focusing on full sentences is through a chronology. In another student's journal, the instructor provided a chronology of the perfect day, modeling how time and a chronology can be written up in English (Figure 8). He illustrated the chronology by including a picture of a person sleeping with a dream bubble above his head. The student, Akari, responded with her own "perfect day" (Figure 9). She illustrated her chronology with a half-moon figure saying "good night" in a speech bubble. This chronology set up an interaction in which the instructor later added an arrow to the word LINE (an app for messaging online) with the comment "I don't know this". Akari later responded "this is a popular communication tool in Japan", indicating she had read back through previous contributions, saw the instructor's comment and assumed that if she responded, the instructor would read it and learn from what she wrote. This interaction validated what the student wrote as part of a dialogue and served to build rapport.

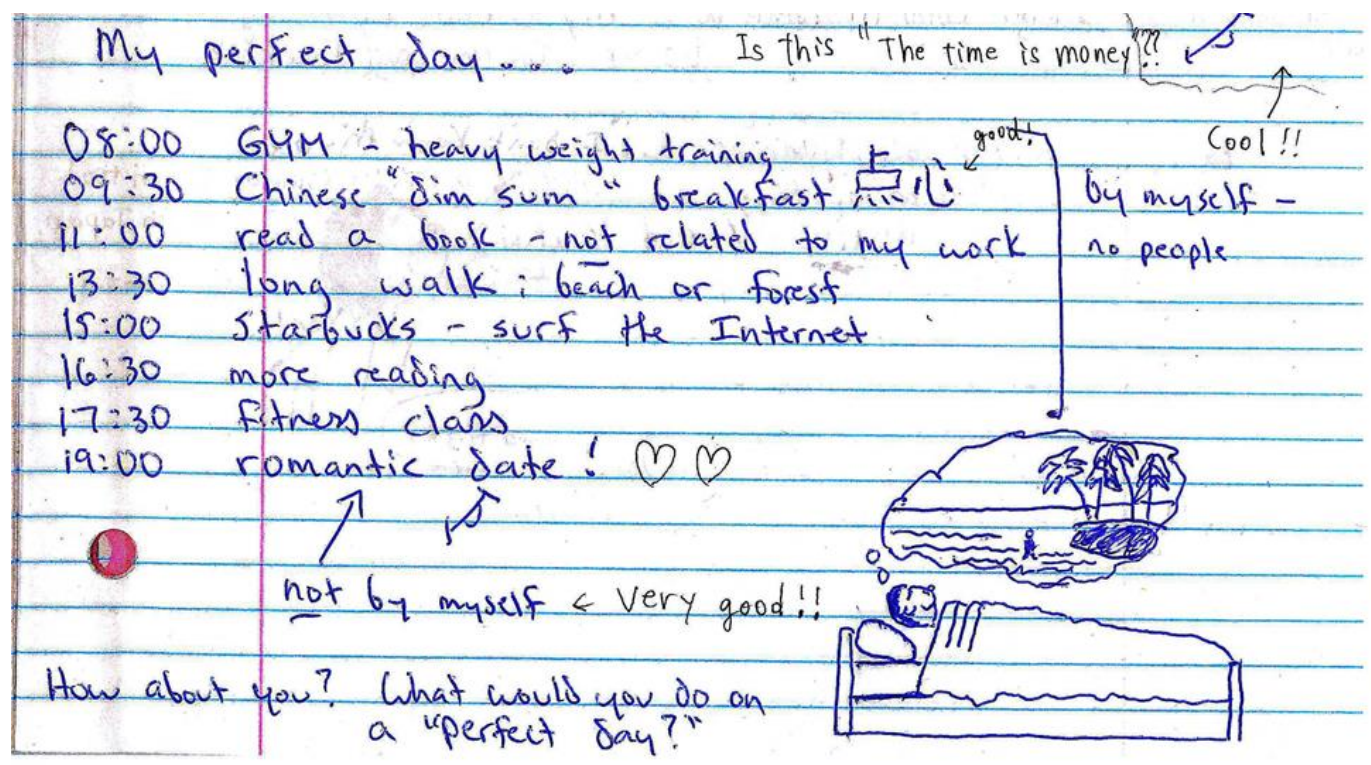

Figure 8. Instructor's Perfect Day Chronology 


\begin{tabular}{|c|c|}
\hline & \\
\hline & $10: 00$ Breakfast - Bagle with cheese, kale, tomato \\
\hline & Milk, Vegitable Soup, Yognlt \\
\hline & 11:00 Shopping at mall- (I went to Chinook Center. \\
\hline & (with iny frends 0 ) Ilike there:? \\
\hline & 14:00 Tea time - I wanna eart with some sweets $D$ \\
\hline & Iate a pooteen". That was good. \\
\hline & I like cakes, cookies, Warabi Mochi \\
\hline & This is Japanese Sweets. \\
\hline & $17=0.0$ Come home and watch TV \\
\hline & 19:00 Dinner with my family at Italian cuison Restavarant \\
\hline & or Sushi Restaurant \\
\hline & 20:00 Take a bath - Ilike takea bath. \\
\hline & $\begin{array}{l}\text { Japanese love soak in the bath } \\
\text { It may take an hour? }\end{array}$ \\
\hline & bath twe It uses many water, but we don't thind. \\
\hline & - \\
\hline & 21:00 Communicate with my friends by using \\
\hline & LINE, Twitter and Facebook \\
\hline & $\uparrow$ \\
\hline & Play games I sonit know this one \\
\hline & This is a Papular communication tool \\
\hline & Watch TV and Youtube \\
\hline & $\begin{array}{l}4 \text { I like Nick Protera. He is amazing } \\
\text { Yes! }\end{array}$ \\
\hline & $24: 00 \cdot G$ \\
\hline
\end{tabular}

Figure 9. Akari's Perfect Day Chronology

Students picked up on the instructor's modeling of other aspects of English writing. For example, Ayumi began her dialogue journal by writing the date in a non-standard way "24.Feb.2015", but after the instructor wrote the date of his entry as "26th February 2015", she used the same format thereafter.

Questioning and requesting. When students are asked questions in the margins of their journal, the purpose was to further a dialogue by engaging with content the student had written. Interestingly, there are few examples where the students commented on statements the instructor made. The data reveals that they only responded when asked a question.

Responding to a comment in Eri's journal on the size of Canadian homes, the instructor wrote: "Yes, Canadians have huge houses. I guess because there is so much available land? Do you have a theory about this?" Beside this Eri wrote her answer. "I think so too. There are so large field, and Canadians make rooms in underground. Then their 
houses are large". She then connected her response to my question by drawing an arrow from her writing to his. The questioning by the instructor resulted in an exchange in the margins that allowed Eri to think more about her initial observation.

In Kota's journal he told the story of getting lost and having to take a taxi home. In a textual response the instructor expressed empathy and encouragement: "I am sorry you lost your way one evening and had to take a taxi home. But I am happy to hear you were able to find a taxi and make it home, even though you were late". To augment this, he also drew a picture of a taxi and asked why he had been late (Figure 10). In response, on the next page of his journal, Kota began by answering the question from the picture, revealing that he had read the response and was treating his next entry as the continuation of the conversation.

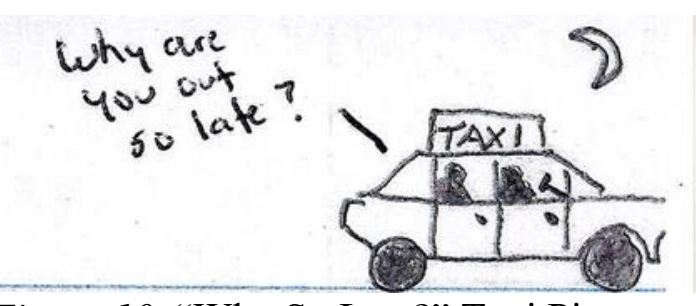

Figure 10. "Why So Late?" Taxi Picture

Sometimes questioning was not effective the first time around. In Akari's journal, following a conversation about places to travel, the instructor drew a picture of a windmill and asked Akari "do you know where this is?". When she responded "windmill?" he realized that she had misunderstood his question as "do you know what this is?". To clarify the misunderstanding he repeated only the question word "where?" which focused her attention and resulted in the correct answer "the Netherlands".

Visual aids linked to questioning enhanced the dialogue between student and instructor. When he used a question in the margins or added a question and a picture, the students usually answered and in some cases, the answers extended the conversation and built on the growing rapport between instructor and student.

Providing feedback. While the emphasis in these dialogue journals was on fluency, at times there were natural opportunities to provide feedback about form, and visual aids, particularly textual enhancements, were used to do so.

In keeping with the conversational nature of dialogue journals, this feedback often took the form of recasting the incorrect usage. Kota wrote about not wanting to put on pounds while in Canada through a lack of exercise (see Figure 11). He wrote "Maybe, I may get weight... because I don't play any sports here. I don't want to get weight". Below this line the instructor responded with a marginal comment that used the correct expression "Oh, I see. You don't want to gain weight", demonstrating that what he had written was not at first clear "Oh, I see" and providing the correct reformulation. 


\begin{tabular}{|c|c|}
\hline $\begin{array}{l}\text { You can buy } \\
\text { at the ticket }\end{array}$ & can buy the ticcet. I want do skerting ( \\
\hline $\begin{array}{l}\text { Shopin } \\
\text { mackwar }\end{array}$ & In near hoke but I don't know where I can do \\
\hline $\begin{array}{l}\text { Hall at } \\
\text { the University. }\end{array}$ & skerting. Maybe, I may get weight... because \\
\hline $\begin{array}{l}\text { Do you } \\
\text { Kaow chere }\end{array}$ & I don't play any sportsin here. I don't want \\
\hline that is? & ro get weight. \\
\hline $\begin{array}{l}\text { Oh, I see } \\
\text { You Son't } \\
\text { to gain }\end{array}$ & $\begin{array}{l}\text { want } \\
\text { weight }\end{array}$ \\
\hline & \\
\hline
\end{tabular}

Figure 11. Feedback on Kota's Word Choice

In keeping with the overarching goal of instilling confidence in L2 writers, when students made spelling mistakes that the instructor felt needed to be corrected, he modeled the correct form without drawing undue attention to the students' errors. Ayumi misspelled dinosaur while describing a class outing to a science museum. She had enhanced her explanation of the trip with a simple picture. The instructor added a comment beside the drawing, and wrote: "a cute dinosaur". Through this drawing and comment he was able to provide written corrective feedback that made sense in context without placing an emphasis on the correction.

While feedback is a response facilitator that the instructor, like the teachers in Werderich's study used, these examples demonstrate how the focus remained on communication through the use of recast in textual enhancements.

\section{Discussion}

Considering the research questions for this study, the findings demonstrate the ways in which visual aids (drawings and textual enhancements) acted as general and specific response facilitators in dialogue journals. As general response facilitators, these visual aids facilitated the dialogic communication between instructor and student by making meaning visual and focusing the reader's attention on relevant passages. As specific response facilitators, the visual aids enhanced the textual modeling, questioning/requesting, and provision of feedback to the students by the instructor.

The data reveals that on their own, students' visual aids reinforced what they were trying to communicate, especially when their vocabulary was limited, as in Mei's drawings to accompany her "what I like" statement. This role is beyond what other researchers imagined when encouraging student drawing as illustrations (Daniels \& Daniels, 2013; Stillman et. al, 2014). Rather these pictures and textual enhancements are part of the dialogue and helped to move the communication forward.

When the instructor used visual aids, it furthered the conversation as well. The 
visual aids underscored the meaning of words, the importance of certain phrases and the presented genres of communication not usually included in dialogue journals (e.g., the icebreaker quiz with Kota). While these students were far from non-literate, as in Peyton's (1993) example, they openly expressed that they might not have understood certain passages without these visual aids.

The visual aids used by the instructor allowed for modeling, questioning/requesting and providing feedback. He modeled quizzes and chronologies; questioned/requested clarification; and provided feedback where written communication was unclear. We argue that his use of visual aids in partnership with other response facilitators, underscored the messages he was sending in each case.

Our findings draw us to revisit and adapt the response facilitator model Werderich (2006) embedded in her conceptualization of teacher responses in dialogue journal. Since the instructor in this study did not make reference to procedural reinforcements, which Werderich defined as visual aids, we do not see a place for those in this model. Within the quadrant of visual aids, we envision stand-alone drawings and textual enhancements (SA visual aids) and those visual aids coupled with the other three response facilitators (VA \& modeling, VA \& questioning/requesting, $\mathrm{VA}^{3} \&$ providing feedback). The resulting revised model is illustrated in Figure 12.

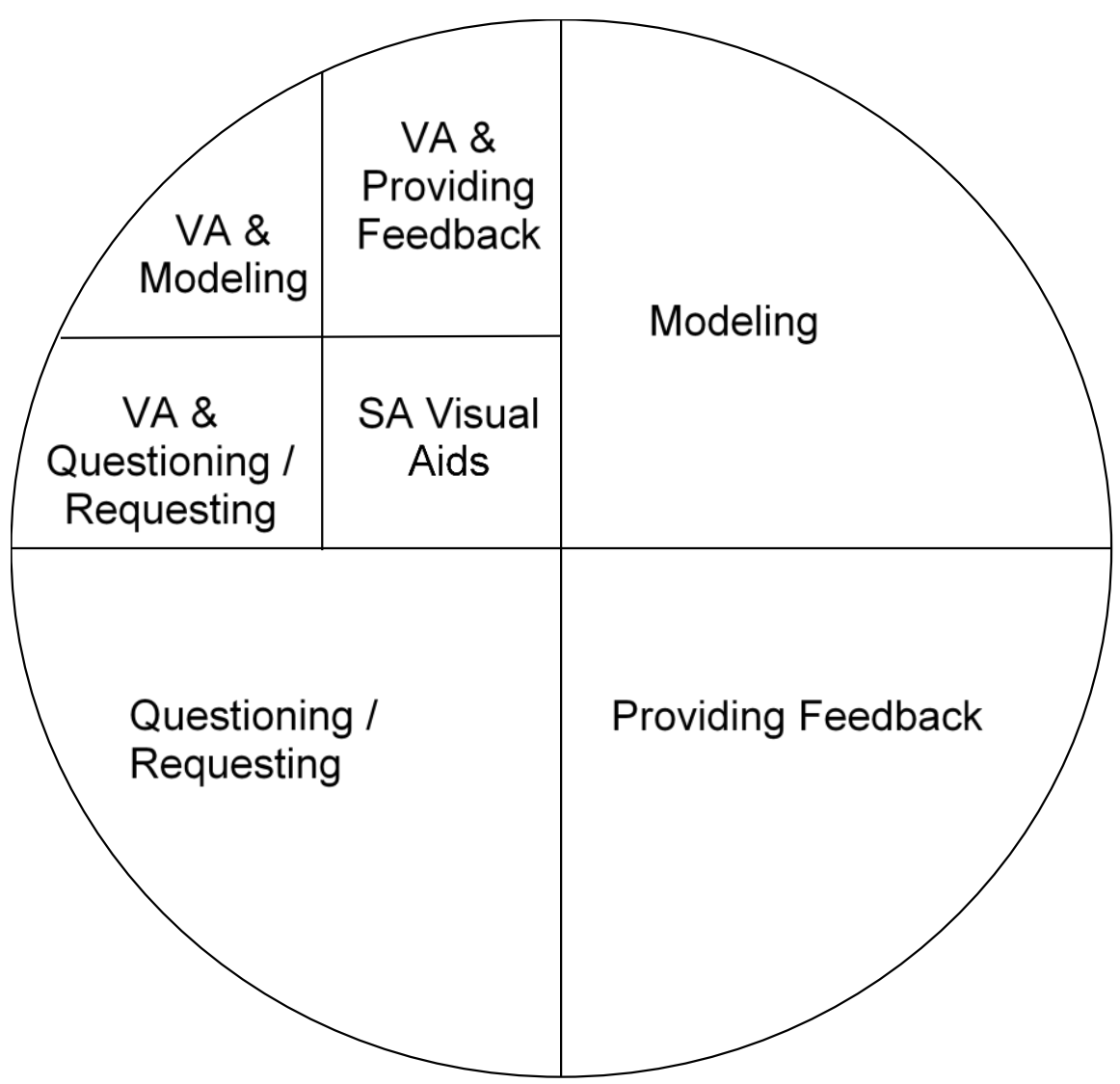

Figure 12: Werderich's Response Facilitators Model (Adapted and Revised)

\footnotetext{
${ }^{3}$ SA: stand-alone; VA: visual aids.
} 


\section{Pedagogical Implications}

Understanding visual aids as response facilitators in dialogue journals, expanded to include instructor- and student-produced drawings and textual enhancements, presents exciting opportunities for language instructors to encourage the development of written fluency, and enhance student-teacher communication. The authors suggest three pedagogical implications arising from the findings of this study.

First, the findings suggest that response facilitators, especially instructor-produced visual aids, can be used by educators to enhance even further the rapport building function for which dialogue journals are well known. The use of textual enhancements served to provide opportunities for extending discussion, and thereby the development of strengthened student-teacher affinity (for example, see the extended discussions surrounding Akari's travel and Kota's taxi ride).

Second, even with the overarching emphasis on instructor-student communication fostered by dialogue journals, our findings indicate that educators particularly concerned with providing corrective feedback on writing need not be concerned that the element of error rectification is overlooked. In fact, the previously cited examples of Kota's unusual collocation of "weight" (see Figure 11), along with Ayumi's misspelling, and the subsequent teacher modelling of standard forms indicate that dialogue journals do indeed provide opportunities for corrective feedback. It may be argued that the nature of dialogue journals affords more occasions for such indirect corrective feedback, and as Ferris (2014) points out in her summary of best practices for teacher response to writing, indirect feedback may well be "more beneficial to long-term student development than direct correction" (p. 8).

Finally, instructor-produced visual aids offer a critical element often overlooked in teacher response practices: the opportunity for feedback to be two-way. Effective feedback is often depicted as a two-way process (e.g., Ferris, Liu and Rabie, 2011). Yet Ferris' (2014) study of writing teachers' response praxis found that few indicated they "regularly asked students to analyze, reflect upon, or respond to feedback" (p. 17). As noted previously, the discussion with Akari regarding the instant messaging application LINE exemplified how textual enhancements enabled the re-reading of, and response to, instructor input.

\section{Conclusions}

This article has shown how response facilitators, in particular instructor-produced visual aids, can be an effective tool in helping students understand and interact with their instructor in dialogue journals. In turn, these visual aids encourage students to enhance their own writing with drawings and textual enhancements, and thus further augmenting the interactive process for which dialogue journals are known. Building upon Werderich's (2006) understanding of visual aids as response facilitators, an alternate definition of visual aids has emerged: one which includes pictures and textual enhancements. We also contend that instructor-created visual aids can enhance and strengthen some of the functions dialogue journals have traditionally been associated with, including modeling, questioning/requesting and feedback. We maintain that this alternate definition of visual aids provides enhanced opportunities for teacher feedback on student writing to be of a two-way nature, in a way that encourages further student reflection, analysis and response. 


\section{References}

Burton, J., \& Carroll, M. (2001). Journal writing as an aid to self-awareness, autonomy, and collaborative learning. In M. C. Jill Burton (Ed.), Journal Writing (pp. 1-7). Alexandria: Teachers of English to Speakers of Other Languages.

Casanave, C. P. (2011). Journal writing in second language education. Ann Arbor: University of Michigan Press.

Daniels, H., \& Daniels, E. (2013). The best-kept teaching secret: How written conversations engage kids, activate learning, and grow fluent writers, $K-12$. Thousand Oaks: Corwin.

Dressler, R., \& Tweedie, M. G. (2016). Dialogue journals in short-term study abroad: “Today I wrote my mind." TESOL Journal, 7(4), 939-967. https://doi.org/10.1002/tesj.254

Ferris, D. (2014). Responding to student writing: Teachers' philosophies and practices. Assessing Writing, 19, 6-23. https://doi.org/10.1016/j.asw.2013.09.004

Ferris, D., Liu, H., \& Rabie, B. (2011). "The job of teaching writing": Teacher views on responding to student writing. Writing and Pedagogy, 3(1), 39-77. doi: 10.1558/wap.v3i1.39

Ghahremani-Ghajara, S., \& Mirhosseini, S. A. (2005). English class or speaking about everything class? Dialogue journal writing as a critical EFL literacy practice in an Iranian high school. Language, Culture and Curriculum, 18(3), 286-299. https://doi.org/10.1080/07908310508668748

Hanrahan, M. (1999). Rethinking science literacy: Enhancing communication and participation in school science through affirmational dialogue journal writing. Journal of Research in Science Teaching, 36(6), 699-717. https://doi.org/10.1002/(SICI)1098-2736(199908)36:6<699::AID-TEA7>3.0.CO;2$P$

Holmes, V. L., \& Moulton, M. R. (1995). A contrarian view of dialogue journals: The case of a reluctant participant. Journal of Second Language Writing, 4(3), 223-251. https://doi.org/10.1016/1060-3743(95)90011-X

Jewell, T. A., \& Pratt, D. (1999). Literature discussions in the primary grades: Children's thoughtful discourse about books and what teachers can do to make it happen. The Reading Teacher, 52(8), 842-850. http://www.jstor.org/stable/20204706

Korgel, B. A. (2002). Nurturing faculty-student dialogue, deep learning and creativity through journal writing exercises. Journal of Engineering Education, 91(1), 143146. https://doi.org/10.1002/j.2168-9830.2002.tb00684.x

Kreeft, J. (1984). Dialogue writing: Bridge from talk to essay writing. Language Arts, 61(2), 141-150. http://www.jstor.org/stable/41405149

Lucas, T. (1990). Personal journal writing as a classroom genre. In J. K. Peyton (Ed.), Students and teachers writing together (pp. 99-123). Alexandria: Teachers of English to Speakers of Other Languages.

Peyton, J. K. (1997). Dialogue journals: Interactive writing to develop language and literacy. Emergency Librarian, 24(5), 46-47+.

Peyton, J. K., \& Reed, L. (1990). Dialogue journal writing with non-native English speakers: A handbook for teachers. Washington, DC: TESOL.

Peyton, J. K., \& Staton, J. (1993). Dialogue journals in the multilingual classroom: Building language fluency and writing skills through written interaction. Norwood, 
NJ: Ablex.

Staton, J. (1987). The power of responding in dialogue journals. In T. Fulwiler (Ed.), The journal book (pp. 47-63). Portsmouth: Heinemann.

Staton, J., Shuy, R. W., Peyton, J. K., \& Reed, L. (1988). Dialogue journal communication: Classroom, linguistic, social and cognitive views. Norwood: Ablex.

Stillman, J., Anderson, L., \& Struthers, K. (2014). Returning to reciprocity: Using dialogue journals to teach and learn. Language Arts, 91(3), 146-160. http://www.jstor.org/stable/24575021

Werderich, D. E. (2006). The teacher's response process in dialogue journals. Reading Horizons, 47(1), 47-73.

Wright, A. (1984). 1000 pictures for teachers to copy. London: Collins ELT.

\section{Author Biographies}

Dr. M. Gregory Tweedie is Associate Professor at the Werklund School of Education, University of Calgary. He has used dialogue journals with English Language Learners in China, Singapore, Malaysia, Qatar, Kazakhstan, Australia and now Canada. He holds a teaching certification as a secondary school teacher in Queensland, Australia.

Dr. Roswita Dressler is an Assistant Professor at the Werklund School of Education, University of Calgary specializing in second language teaching. As Director - Teaching Across Borders, she has studied the use of dialogue journals with ELLs from Japan. She is a former K-12 teacher of French and German. 